\title{
Infraestructura
}

A.R. Hace solo unos días estuve en la presentación del segundo libro de poesía de César Fernández Rollán periodista, novelista, guionista, poeta y amigo. Durante el acto se recitaron algunos de sus poemas. Uno de ellos, titulado Libreme Dios, me transportó en un microsegundo de vuelta al mundo de la arquitectura, mostrándome una vez más lo ligados que están todos los ámbitos de las artes y que las verdades lo son siempre, se miren como se miren y desde donde se miren.

\section{Decía así:}

Líbreme Dios de lo banal.

De lo vacío.

De lo vacuo.

Revuélvanse mis entrañas

cuando me deje embriagar por la forma,

por el artificio. Por lo vano.

Córtenme los dedos de la zurda uno a uno,

si sucumbo a la pedantería.

Arránquenme el corazón de cuajo

si por vestirme de domingo y de punta en blanco

cubro en demasía la carne imperfecta

que habita debajo.

La sangre roja y caliente de mi tuétano.

Estas palabras, de otro César, me hicieron recordar la obra de César Ortiz-Echagüe, el maestro sobre el que gira rita_15.

J.P.A. + J.N. Durante la XI Bienal Iberoamericana de Arquitectura y Urbanismo, celebrada en Asunción en octubre 2019, José Manuel Pozo nos presentaba la obra de Ortiz-Echagüe.

En aquella ocasión impactaba la comparativa de la obra de César con muchas de las conversaciones y discusiones que se producían en los diferentes foros de la Bienal.

Hoy, un año en pandemia después, cobra un valor especial lo intrínseco del trabajo del arquitecto. Sacando de la ecuación las escalas y presupuestos de algunos de estos proyectos, nos queda como sostenedor de la esencia un diálogo indisoluble entre estructura y oportunidad. Es esta estructura la que permite y facilita un diseño de lo justo y necesario, con la flexibilidad y versatilidad que da un rigor firme al que volver.

El 2020 nos obliga a reenfocar nuestra disciplina y obras como la SEAT nos enseñan la vocación de servicio de esas estructuras capaces de adaptarse a la evolución de la sociedad. Parece que nos guían hacia un modelo de arquitectura en el 
que nuestro aporte sea simplemente (¿parece fácil?) establecer los soportes en los que cada uno propondrá su uso y disfrute. Es una gran responsabilidad dibujar el campo de juego, pero no participar en las reglas ni en el o los partidos que se puedan jugar simultáneamente.

La bonita oportunidad que se nos ofreció desde la dirección de rita_de participar en el armado de este número, sin duda nos enfrentó a entender la profunda actualidad de uno de los elementos más antiguos, sino el primero, de la arquitectura: la estructura; y cómo esta estructura y su sentido físico y matemático no deja lugar a lo aleatorio y superfluo, desde ella hoy se pueden alimentar las oportunidades de ocupación y transformación que nuestra sociedad demanda. Nada falta y nada sobra en un diseño estructural preciso, pero todo cabe y todo puede ser de una estructura con vocación de servicio.

J.P.A. + J.N. + A.R. Las obras aquí seleccionadas entendemos que parten de esa vocación. Con las geometrías más esenciales apuntan a una pertinencia de diseño, ofrecen un "rayado de cancha" para permitirnos jugar como y cuando queramos. Obras que ligan la sobrevalorada apariencia actual a su esquema estructural, a su orden interno, a su razón de existir. Las camisetas, escudos, banderas y afición, o sea, las terminaciones, las pone el usuario del espacio. Son obras sin acabar porque no saben cómo acabarán, son obra gruesa en constante transformación y funcionamiento.

Un cobertizo preexistente al que la estructura no solo protege del agua, sino que le ofrece una oportunidad en el espesor que genera entre exterior e interior. Un museo que utiliza la estructura como soporte de un argumento. Una cubierta a dos aguas cuya estructura absorbe y genera libertad de uso. Una playa a la que la imposición de un orden estructural perimetral caracteriza y jerarquiza. En general estructuras precisamente diseñadas y colocadas para abrir un abanico innumerable de posibilidades.

Entre las obras seleccionadas, la de Oficios Asociados (OOAA) nos hizo, no solo reafirmar el argumento, sino también entenderlo como progresivo y evolutivo. Cuando contactamos con el estudio por el proyecto de su oficina taller, nos informaron de que lo habían "desarmado" y trasladado a una nueva ubicación. Esto abre una aún más sugerente reflexión sobre el valor estructural que, en su estandarizado y dimensionado preciso, permite no solo albergar diferentes "juegos" sino también cambiar de localización.

Prestar especial atención a la estructura nos permite entender el carácter infraestructural que puede tener la arquitectura, aquella que reúne las condiciones pertinentes y suficientes para el desarrollo de la vida.

Juan Paulo Alarcón 